\title{
INTERESES DE PRESTAMOS DE DINERO. LIMITACIONES LEGALES Y EFECTOS CIVILES DE SU ABUSIVIDAD EN EL DERECHO ROMANO
}

\author{
Carmen Lopez-Rendo Rodríguez \\ Profesora Catedrática de la Universidad de Oviedo \\ clrendo@uniovi.es
}

RESUMEN: El trabajo estudia las limitaciones a los intereses en las diferentes épocas establecidas por la ley de las XII Tablas, las leges foneraticias y los emperadores en las épocas postclásicas y justinianea para posteriormente reseñar las consecuencias civiles de acordar/pactar intereses ilegítimos. El estudio finaliza con unas conclusiones en las que se refleja la aplicación de las soluciones juridicas romanas al problema planteado por las clausulas suelo en el derecho español.

PALABRAS CLAVES: La usura. Usurae centesimae. Evolución histórica de las limitaciones a los tipos de interés en el Derecho romano. Usurae supra legitimun modum.

\section{Juros de empréstimo de dinheiro. Limitações legais e efeitos civis da sua abusividade no Direito Romano}

RESUMO: O trabalho estuda as limitações aos juros nas diferentes épocas estabelecidas pela Lei das XII Tábuas, as leges foneraticias e os imperadores nos períodos pós-clássicos e justinianeu para posteriormente revisar as conseqüências civis de concordar / pactuar juros ilegítimos. $\mathrm{O}$ estudo encerra com algumas conclusões em que se reflete a aplicação das soluções jurídicas romanas ao problema levantado pelas cláusulas de base na lei espanhola.

PALAVRAS-CHAVE: Usura. Usurae centesimae. Evolução histórica das limitações aos tipos de juros no Direito Romano. Usurae supra legitimun modum.

\section{Interest of money loans. Legal limitations and civil effects of his abusivity in roman law}

ABSTRACT: The work studies the limitations to interests in different times established by the law of the XII Tables, the leges foneraticias and the emperors in the post-classic and justinian times to later review the civil consequences of agreeing / pacting illegitimate interests. The study finishes with some conclusions in which the application of the Roman legal solutions to the problem raised by the ground clauses in Spanish law is reflected.

KEYWORDS: Usury; Usurae centesimae; Historical evolution of the limitations on interest rates in Roman Law; Usurae supra legitimun modum.

\section{INTRODUCCION}

He elegido este tema de gran actualidad en el ámbito social, económico y jurídico con la finalidad de destacar la consideración que en el derecho romano tenían los intereses de los préstamos, así como las limitaciones normativas que fueron estableciéndose en cada época, y las consecuencias civiles que el ordenamiento jurídico romano estableció en casos de incumplimientos. 
Intereses de prestamos de dinero: limitaciones legales y efectos civiles de su abusividade em el Derecho Romano

En España y en los tribunales españoles, desde el año 2013, como consecuencia de la crisis económica, se han venido produciendo unas reclamaciones de los consumidores contra las entidades bancarias con fundamento en unas cláusulas limitativas de interés variable de préstamos con garantía hipotecaria, conocidas en la doctrina y en la práctica diaria con el nombre de cláusulas suelo o cláusula suelo/techo ${ }^{1}$, que han llegado hasta el Tribunal Supremo ${ }^{2}$ y hasta el TJUE, cuya gran sala dictó Sentencia el 21 de diciembre de 2016 en los asuntos acumulados C-154/15, C-307/15 y C-308/15, ${ }^{3}$

Ante las respuestas jurídicas de los Tribunales españoles ${ }^{4}$, he creido conveniente analizar las fuentes del Derecho romano, en las que se encuentran normas, y principios aplicables a los préstamos de dinero que devengaban intereses, que abordan cuestiones de especial importancia en esta materia, tales como la naturaleza de los intereses, causas de los mismos, limita-

1 Me estoy refiriendo a este tipo de cláusulas que contienen las escrituras de préstamos hipotecarios: “3. bis. 3. Límites a la variación del tipo de interés. En todo caso, aunque el valor del índice de referencia que resulte de aplicación sea inferior al 2'50\%, éste valor, adicionado con los puntos porcentuales expresados anteriormente para cada supuesto, determinará el "tipo de interés vigente" en el "período de interés". Todo ello, sin perjuicio de la aplicación en su caso de la bonificación prevista en el apartado siguiente. El tipo aplicable al devengo de los intereses ordinarios no podrá ser, en ningún caso, superior al $15 \%$ nominal anual”.

La inclusión de las cláusulas suelo en España, ha sido una práctica habitual desde el comienzo de la burbuja inmobiliaria, que duró desde 1997-1998 hasta el año 2007, en que se produjo el estallido. La mayoría de las hipotecas suscritas a partir de esos años, tenían un interés variable (normalmente Euribor mas un diferencial) y un límite (suelo) a pagar por el deudor, aunque el Euribor mas el porcentaje fijado por el banco fuera menor.

2 Aun cuando las llamadas "cláusula suelo" sean lícitas, ello no significa que su incorporación en el contrato se pueda haber realizado sin advertir claramente al contratante que su contrato tiene en las cláusulas de su préstamo hipotecario un límite mínimo al interés variable y sin que conste el convencimiento de que el consumidor ha comprendido lo que ello supone, pues en caso contrario la falta de la necesaria "claridad y trasparencia" convertirá a la cláusula en abusiva. Por ello el Tribunal Supremo en la STS (sala civil) 9 de mayo de 2013, ha dejado claro que: "Las cláusulas suelo son lícitas siempre que su transparencia permita al consumidor identificar la cláusula como definidora del objeto principal del contrato y conocer el real reparto de riesgos de la variabilidad de los tipos. Es necesario que esté perfectamente informado del comportamiento previsible del índice de referencia cuando menos a corto plazo, de tal forma que cuando el suelo estipulado lo haga previsible, esté informado de que lo estipulado es un préstamo a interés fijo mínimo, en el que las variaciones del tipo de referencia a la baja probablemente no repercutirán o lo harán de forma imperceptible en su beneficio" STS (Sala civil) 9 de mayo de 2013. Núm.241/2013. Ponente. Excmo. Sr. Don Rafael Gimeno Bayón Cobos. Cendoj Roj. STS 1916/2013. La votación y fallo se produjo el 19 de marzo de 2013. Fundamento jurídico decimoquinto, parágrafo 256

3 STJUE 21 de diciembre 2016: https://ep00.epimg.net/descargables/2016/12/21/ 26aea35b8c66e78f3169264b9f90ecbe.pdf. El Tribunal de Justicia (Gran Sala) declara: El artículo 6, apartado 1, de la Directiva 93/13/CEE del Consejo, de 5 de abril de 1993, sobre las cláusulas abusivas en los contratos celebrados con consumidores, debe interpretarse en el sentido de que se opone a una jurisprudencia nacional que limita en el tiempo los efectos restitutorios vinculados a la declaración del carácter abusivo, en el sentido del artículo 3, apartado 1 , de dicha Directiva, de una cláusula contenida en un contrato celebrado con un consumidor por un profesional, circunscribiendo tales efectos restitutorios exclusivamente a las cantidades pagadas indebidamente en aplicación de tal cláusula con posterioridad al pronunciamiento de la resolución judicial mediante la que se declaró el carácter abusivo de la cláusula en cuestión.

4 STS (Sala civil) 9 de mayo de 2013. Núm.241/2013. Ponente. Excmo. Sr. Don Rafael Gimeno Bayón Cobos. Cendoj Roj. STS 1916/2013. Auto de aclaración de 3 de junio de 2013. http://www.poderjudicial.es/cgpj/es/ Poder_Judicial/Noticias_Judiciales/

Pleno_de_la_Sala_I_del_Tribunal_Supremo_resuelve_la_peticion_de_aclaracion_sobre_su_sentencia_relativa_a_la s_clausulas_suelo_en_hipotecas. STS (Sala civil) de 8 de septiembre de 2014, núm 464/2014. Ponente: Excmo. Sr. Francisco Javier Orduña Moreno Roj: STS 3903/2014. Id Cendoj: 28079119912014100017. http:// www.poderjudicial.es/search/documento/TS/7195886/Clausulas\%20abusivas/20141024.

Se trata de una sentencia del Pleno del Tribunal Supremo, que cuenta con el voto particular emitido por el Magistrado Excmo. Sr. Sancho Gargallo. STS (Sala Civil) de 25 de marzo de 2015, núm. 139. Ponente: Excmo. Sr. Eduardo Baena Ruiz. Id Cendoj: 28079119912015100015. Vid. REDONDO TRIGO, F., "Acerca de la limitación de la retroactividad de la "cláusula suelo" en la sentencia del Tribunal Supremo de 25 de marzo de 2015 en base al régimen general restitutorio de la nulidad y al Orden Publico" en RCDI n750, pp.2385-2404- STS (Sala civil) de 29 de abril de 2015 núm 222/2015. Ponente: Excmo. Sr. Rafael Saraza Jimena. Id Cendoj: 28079110012015100275. 2.1.5. STS (Sala Civil) de 23 de diciembre de 2015. Pleno. Núm: 705. Ponente: Excmo. Sr. D. Pedro José Vela Torres 
ciones legales, consecuencias del incumplimiento de las limitaciones legales, entre otras. Todas estas cuestiones son las que serán abordadas en el presente trabajo.

\section{NATURALEZA Y CAUSA DE LOS INTERESES}

El interés puede ser visto como precio por el uso o cesión del dinero- usus aris- o bien en el sentido de compensación por el riesgo del mutuante, que utiliza Paulo en un fragmento de comentarios al Edicto, libro 32.1 contenido en D. 17.2.67.1 ${ }^{5}$, en el que, a propósito del reparto de los intereses percibidos de un préstamo de dinero efectuado por uno de los socios, que no era socio de todos los bienes, aclara que debe repartir los intereses, solamente si hubiera prestado en nombre de la sociedad, porque si lo hizo en su propio nombre, nam in suo nomine, debe retener los intereses, puesto que a él le habrá pertenecido el riesgo del capital, quoniam sortis periculum ad eum pertinuerit.

En Derecho clásico romano, Pomponio, en un texto recogido en Comentario a Quinto Mucio, libro VI, que nos transmite D.50.16.1216 , deja claro que el interés que se percibe del dinero no entra en los frutos porque no proviene del mismo capital, sino de otra causa, esto es, de nueva obligación. Papiniano en D.6.1.62 pr. ${ }^{7}$, destaca que el interés no proviene de la naturaleza sino que se percibe por el derecho: “ usura non natura pervenit, sed iure percipitur”.

La causa de los intereses varía según las épocas, de tal forma que en el derecho clásico el interés nace mediante una stipulatio adicional al contrato de préstamo- mutuo, mientras que en el derecho justinianeo, el derecho a cobrar intereses en un contrato de préstamo nacia ya de una disposición normativa, aun cuando no hubiera existido escrito.

En el Derecho clásico romano, los intereses en un principio debían pactarse mediante una stipulatio adicional al contrato de préstamo-mutuo ${ }^{8}$, tal como lo resalta Africano en D.19.5.24: "pecuniae quidem creditae usuras, nisi in stipulationem deductas, non deberi" 9 . Si

5 D.17.2.67.1 Paulo; Comentarios al Edicto, libro XXXII: “1. Si unus ex sociis, qui non totorum bonorum socii erant, communem pecuniam faeneraverit usurasque perceperit, ita demum usuras partiri debet, si societatis nomine faeneraverit: nam si suo nomine, quoniam sortis periculum ad eum pertinuerit, usuras ipsum retinere oportet".

6 D.50.16.121 Pomponius libro VI ad Quintum Mucium: Usura pecuniae, quam percipimus, in fructu non est, quia non ex ipso corpore, sed ex alia causa est, id est nova obligatione.

7 D.6.1.62 pr Papinianus libro VI quaestionum: "Si navis a malae fidei possessore petatur, et fructus aestimandi sunt, ut in taberna et area quae locari solent. Quod non est ei contrarium, quod de pecunia deposita, quam heres non attingit, usuras praestare non cogitur: nam etsi maxime vectura sicut usura non natura pervenit, sed iure percipitur, tamen ideo vectura desiderari potest, quoniam periculum navis possessor petitori praestare non debet, cum pecunia periculo dantis faeneretur".

8 Isidoro de Sevilla 5, 25, 18: Mutuum appellatum est quia id, quod a me tibi datur, ex meo tuum fit. Vid. GIUFFRE, V., La datio mutui. Prospettive romane e moderne, Napoli, 1989. Herrera Bravo, R: Usurae. Problemática jurídica de los intereses en Derecho romano, Jaen, 1997; SAlAZAR REVUELTA, M: La gratuidad del "mutuum" en el Derecho romano, Jaén, 1999. ARNESE, A., Usura e modus: Il problema del sovraindebitamento dal mondo antico all 'attualità. Bari, 2013.

9 D. 19.5.24, Africanus libro octavo quaestionum: Titius Sempronio triginta dedit pactique sunt, ut ex reditu eius pecuniae tributum, quod Titius pendere deberet, Sempronius praestaret computatis usuris semissibus, quantoque minus tributorum nomine praestitum foret, quam earum usurarum quantitas esset, ut id Titio restitueret, quod amplius praestitum esset, id ex sorte decederet, aut, si et sortem et usuras summa tributorum excessisset, id quod amplius esset Titius Sempronio praestaret: neque de ea re ulla stipulatio interposita est. Titius consulebat, id quod amplius ex usuris Sempronius redegisset, quam tributorum nomine praestitisset, qua actione ab eo consequi possit. Respondit pecuniae quidem creditae usuras nisi in stipulationem deductas non deberi: verum in proposito videndum, ne non tam faenerata pecunia intellegi debeat, quam quasi mandatum inter eos contractum, nisi quod ultra semissem consecuturus esset: sed ne ipsius quidem sortis petitionem pecuniae creditae fuisse, quando, si Sempronius eam pecuniam sine dolo malo vel amisisset vel vacuam habuisset, dicendum nihil eum eo nomine praestare debuisse. Quare tutius esse praescriptis verbis in factum actionem dari, praesertim cum illud quoque convenisset, ut quod 
Intereses de prestamos de dinero: limitaciones legales y efectos civiles de su abusividade em el Derecho Romano

por un préstamo, el accipiens adquiere otra deuda extraordinaria por encima de la restitución, no es a consecuencia de la traditio, tal como transmite Paulo en los comentarios al libro III ad edictum recogidos en D. 2, $14,17 \mathrm{pr}^{10}$, sino que esa se origina por una stipulatio, que es una causa autónoma e independiente de la entrega.

El simple pacto no producía acción alguna para reclamar intereses, pero sí se concedía al deudor una exceptio a oponer a la reclamación del acreedor, alegando que eran indebidos ${ }^{11}$.

Esta exigencia y consideración quiebra en la época justinianea, y la Novela $136.4^{12}(\mathrm{del}$ 564), concede a los banqueros el derecho de cobrar un interés del $8 \%$ incluso sin escrito- no solum ex stipulatione, sed etiam ex non scripto tales usuras illis dari quales lex illis stipulari concedit, hoc est usque ad bessem centesimae-.

Justiniano lo explica argumentando, que se dice que vulgarmente los intereses no surgen sin estipulación, y son muchos los casos en que nacen sin estipulación, del solo pacto, y a veces ni siquiera en virtud de pacto, sino que son exigidos "automáticamente". El fundamento de esta disposición lo expresa en la conclusión de esta novela, indicando:"no sería justo que quienes están dispuestos a ayudar a todos los necesitados, sufriesen injusticia por tal sutileza": "Nam qui omnibus fere indigentibus opem ferre parati sunt, iustum non est eiusmodi subtilitate laedi".

La misma Novela, capítulo 5, parágrafo $1^{13}$ admite la validez de los pactos de intereses, y contempla dos presunciones iuris et de iure, en las que se permite al acreedor exigir el $8 \%$ de interés: 1. Futuros mutuos, pactados por escrito, en los que se contrata un mutuo con intereses, pero no se ha determinado el porcentaje de interés, de tal forma que los prestatarios no pueden oponer la gratuidad del mutuo, presumiéndose el interés del 8\%, como si expresamente se

amplius praestitum esset, quam ex usuris redigeretur, sorti decederet: quod ipsum ius et causam pecuniae creditae excedat. GIUfFre, V, La datio mutui. Prospettive romane e moderna, Napoli 1989.

${ }^{10}$ D.2.14.17 pr Paulus libro III ad edictum: Si tibi decem dem et paciscar, ut viginti mihi debeantur, non nascitur obligatio ultra decem: re enim non potest obligatio contrahi, nisi quatenus datum sit.

${ }^{11}$ D.2.14.7.4, Ulpianus libro IV ad edictum: "Sed cum nulla subest causa, propter conventionem hic constat non posse constitui obligationem: igitur nuda pactio obligationem non parit, sed parit exceptionem».

D 12.6.26.3, Ulpianus, libro XXVI ad edictum: "Indebitum autem solutum accipiemus non solum si omnino non debeatur, sed et si per aliquam exceptionem perpetuam peti non poterat: quare hoc quoque repeti poterit, nisi sciens se tutum exceptione solvit $\gg$.

D.46.3.102.1, Scaevola, libro V Responsorum: “1. Cum de sorte debita constaret, de usura litigatum esset, novissime ex appellatione pronuntiatum est solutas quidem usuras non repeti, in futurum vero non deberi: quaero, pecunia data utrum usuris cedere deberet, quod petitor defenderet, an vero sorti proficeret. Respondi, si qui dabat, in sortem se dare dixisset, usuris non debere proficere ».

12 Nov.,136.4: “Quoniam vero legem tulimus, ne argentariae mensae praepositi ultra besses usuras fenerentur,ilii autem nos docuerunt, etiam sine scripto se fenerari solere, quantum vero ad usuras, fidem sibi non servari, utpote mutuo sine scriptis contracto nec stipulatione interposita, (iuxta vulgatum illud, non convenire, ut usurae absque stipulatione currant, licet multi sint casus, in quibus non stipulatae etiam usurae, vel ex solo pacto nascuntur, nonnunquam etiam ne quidem ex pactis, sed sua sponte introductae tamen exiguntur) propterea etiam sancimus, non solum ex stipulatione, sed etiam ex non scripto tales usuras illis dari, quales lex illis stipulari concedit, hoc est usque ad bessem centesimae. Nam qui omnibus fere indigentibus opem ferre parati sunt, iustum non est eiusmodi subtilitate laedi”. DIAZ BAUTISTA, A : Estudios sobre la banca bizantina (negocios bancarios en la legislación de justiniano), Universidad de Murcia, 1987, pp.,34 ss.

13 Nov.136.5.1 1: Quodsi vero usuras certas pepigerint, pactae valeant. Si vero hoc solum scriptum sit, mutuum sub usuris contractum esse, contrahentes nequeant dicere, quia usurae deflnitae non sunt, propterea pecuniam non fenebrem esse, sed per praesumtionem ita fiat exactio, quasi besses usurae expresse nominatae sint. Atque hoc quidem in posterum servetur. In rationibus vero iam confectis, etsi mentio usurarum facta non sit (quoniam manifestum est, apud omnem argentariae mensae praepositum contractus sub usuris celebrari, et qui ipse usuras solvit, sine usuris expensam facere non posse), liceat; iis besses usuras exigere, ut tamen in posterum ea observent, quae illis haec sacra lex largitur. DIAZ BAUTISTA, A : Estudios sobre la banca bizantina (negocios bancarios en la legislación de justiniano), Universidad de Murcia, 1987, pp.,37 ss 
hubiera mencionado. 2. Mutuos ya realizados en los que no se ha hecho mención a interés alguno.

La justificación de ésta medida legislativa está basada en la onerosidad inherente a los contratos bancarios, tal como dice expresamente: como quiera que es manifiesto que con todo el que está al frente de un establecimiento de banco los contratos se celebran con intereses, y que el mismo que paga intereses no puede hacer desembolsos sin intereses.

\section{LIMITACIONES A LOS INTERESES}

En el derecho romano la voluntad de las partes a la hora de establecer los intereses estaba sujeta a limitaciones, consistentes por un lado en no superar una determinada tasa de intereses, que va variando en las diferentes épocas, y oscila entre el $12 \%$ anual y el $6 \%$ anual que establece Justiniano con carácter general y por otro lado, tampoco estaba permitido estipular usurae ultra sortis summam ni ultra duplum o supra duplum, es decir, no podía estipularse intereses que superasen el capital, y mucho menos los que superasen el doble del capital ${ }^{14}$.

Por ello es conveniente exponer cuales fueron esos límites, y qué consecuencias estableció el ordenamiento jurídico romano en los supuestos de acordar o pactar intereses supra legitimum.

La palabra latina que se utilizó para designar el interés en principio fue foenus ${ }^{15}$ y usu$r a e^{16}$. Estos intereses se medían en un tanto por ciento del capital-sors ${ }^{17}$ que fue variando a lo largo de las diferentes etapas del derecho romano ${ }^{18}$.

\footnotetext{
${ }^{14}$ Vid. D. 12.6.26.1; CJ 4.32.10

${ }^{15}$ Varrón, según Aulo Gelio 16,12, define Foenus de la siguiente forma: "dictum a fetu et quasi a fetura quadam pecuniae parientis atque increscentis”. Herrera Bravo, R.: Usurae. Problemática jurídica de los intereses en Derecho romano, Jaen, 1997, p.24, 25: "Faenus deriva de la palabra griega $\pi$ oivĩ que significa no solamente pena, sino también premio o recompensa, y es usada para aquellos intereses que se acuerdan en el momento del préstamo de dinero, y para el otro tipo de intereses se adoptam los términos "usura” y "usurae" (D.24,2,2,4). "Faenus" equivale a ganancias o lucro y mas concretamente al interés del dinero prestado. Con Respecto a su etimología Aulo Gelio después de ridiculizar algunas etimologías sobre dichas palabras, parece aprobar la de Varron, el cual según Gelio en el Libro III de su tratado "Sobre Lengua Latina" nos dice que "Faenerator" viene de "Faenus" y que Faenus deriva de Fetus (producto), a causa del producto del dinero que se multiplica (....)”.

${ }^{16}$ Usurae, vid Varron, De linguae latinae, 1. 5, 36,183, "a quo usura, quod in sorte accedebat, impendium appellatum; quae quom accederet ad sortem, usu usura dicta, ut sors quod suum fit sorte”. Isidoro de Sevilla Etymlogiae 5.25.15 Vsura est incrementum fenoris, ab usu aeris crediti nuncupata. CERVENCA, G., Usura (Dir. rom.), en EdD 45 (1992), p. 1126. Brassiello, U., V. Usura. .NNDDI, Torino, 1957, pp.368 y ss; NoODT, G., De foenore et usuris.Opera Omnia I. Colonia, 1763; ScialoJa,V, “Unciarium Fenus”. Studi Giuridici II. Roma, 1934., pp. 287 y ss. Herrera Bravo, R., Usurae. Problemática jurídica de los intereses en Derecho romano, Jaen, 1997, p 22 indica que la expresión "usurae" deriva etimológicamente de "usus", también del término latino e "utor", equivalente a usar, hacer uso y sobre todo significa provecho y utilidad, pero también precio e interés, esto es provecho que se obtiene de lo que se ha prestado. Consiste en la remuneración que el deudor de dinero o de otras cosas, ha de satisfacer al acreedor por la privación que para él supone el no disfrute del capital debido (sors). El término tiene para los romanos el simbolico significado de intereses, y no el de intereses excesivos, que nosotros los modernos llamamos usurarios". ToRrent, A. Diccionario de Derecho romano, Madrid 2005, p. 1426-1427 quien afirma que en latín reciben la denominación de usurae los intereses convencionales también llamados fenora. DE LA RosA DIEZ, P:" Aspectos del préstamo con interés en derecho romano. Estudios de derecho de obligaciones". Homenaje al profesor Mariano Alonso Pérez. Vol.I. Las Rozas, Madrid, 2006., pp.501 y ss.

17 Torrent, A., Diccionario de derecho romano, ob. cit, p. 1426 matiza que sors literalmente significa suerte, hecho aleatorio, quizá por el riesgo que envolvía toda operación de crédito sujeta a la eventualidad de no restitución.

18 Vid. APPLETON CH.: "Contribution à l'histoire du prêt à intérêt à Rome. Le taux du 'fenus anciarium', NRHD, Paris 1919, XLIII, pp.467 y ss; BIANCHINI M.G., La disciplina degli interessi convenzionali nella legislazione giustinianea en Studi in o A. Biscardi II. Milano, 1982, pp. 389 y ss; SAlaZAR Revuelta, M. La gratuidad del mutuum en el Derecho romano. Jaen, 1999, pp 174 y ss. SOLIDORO MARUOTTI, L, “Tassi usurari e giurisdizione”. Diritto@storia.
} 
Intereses de prestamos de dinero: limitaciones legales y efectos civiles de su abusividade em el Derecho Romano

En la Ley de las XII Tablas, en la tabla 8.18 a y b se señala una tasa de interés determinada como límite: el foenus unciarium ${ }^{19}$.

T.8.18a. (Tac, Ann.6.16.2): XII tabulis sanctum, ne quis unciario fenore amplius exerceret -Está sancionado por las XII Tablas que alguien cobre más de una uncia de interés.

T.8.18b. (Cato, Agr. Praef.): Maiores...in legibus posiverunt furem dupli condemnari, feneratorem quadrupli.-Nuestros antepasados... establecieron en las leyes que el ladrón fuera condenado al doble y el usurero al cuádruple.

TORRENT ${ }^{20}$ pone de relieve que no está claro si este tipo de interés era mensual o anual, ni si el año era de diez meses, propio del antiguo calendario romano en cuyo caso el tipo de interés seria el $8,33 \%$ o de 12 meses (en este caso $10 \%$ ).

Las leyes Liciniae Sextiae (367 a. C.), de aere alieno, permitían al deudor insolvente la imputación al capital de los intereses pagados por los préstamos de dinero, y el fraccionamiento de sus pagos en tres anualidades iguales ${ }^{21}$.

Lex Duilia Memnenia de unciario fenore $(357 \mathrm{aC})$ hace referencia al interés del 1 por ciento $^{22}$. Otro plebiscito, de fenore semiunciarium, del año 347 a. C., redujo el tipo de interés

Rivista Internazionale di Scienze giuridiche e tradizione romana, 7, 2008, URL: http://www.dirittoestoria.it/7/ Memorie/Solidoro-Tassi-usurari-giurisdizione.htm

${ }^{19}$ La uncia comprendía la doceava parte del as. Sobre el foenus unciarium vid. William Smith, LLD, WILLIAM WAYTE, G. E. MARINDIN, Ed A Dictionary of Greek and Roman Antiquities, London, 1890 “(...) Niebuhr reckons the fenus unciarium on the year of ten months, so that it would amount to 10 per cent on the year of twelve months; and in this he is followed by Huschke (Recht des Nexum, p. 98 ff.) and Mommsen (Röm. Gesch., i. 3 274=1.220 tr. Dickson), while Walter (Gesch. des Röm. Rechts, \$ 609) and Steuber understand $81 / 3$ per cent on the full year. The treatise of Steuber (Der Zinsfuss bei den Römern, Basel, 1857). collects and criticises the recent literature of the subject. For the year of ten months, see CALENDARIUM p. 341 a." APPLETON, C., " Contribution à 1'histoire du prêt à intéret a Rome: le taux du fenus unciarum » en RHD 43(1919) 467 y ss; PIKULSKA, A, "Fenus unciarium », RIDA 40 (2000), 165 y ss. TORRENT, A., Diccionario de derecho romano, ob., cit p. 569 indica (...)" El fenus unciarium de XII Tab. 8,18, que la situaba en la doceava parte (uncia) al mes del capital prestado que arrojaba la escalofriante cifra del $100 \%$ anual".

20 TorRent, A., Diccionario de derecho romano, ob., cit p.360. JiMENEZ MuÑOZ, F.J., La usura. Evolución histórica y patología de los intereses, Madrid, 2010., p.27, n. 24, el tipo de interés de la ley de las XII Tablas se situaba en un $8,33 \%$ en el primitivo año de 10 meses y en un $10 \%$ en los posteriores de 12 meses. Destaca que no se señala si los intereses eran mensuales o anuales, si bien en la nota 25 advierte que si fueran mensuales alcanzarían un 83,335 en un año de 10 meses y un $100 \%$ en el año de 12 meses. Robert Whiston, Ma. Esto ha sido interpretado de diversas formas para significar, (1) una doceava parte de la centesima paga mensualmente, es decir, un uno por ciento por año; y (2) una doceava parte del principal se paga mensualmente, o cien por ciento al año. Niebuhr refuta largamente las dos opiniones; pero puede ser suficiente para observar que una es incompatible con el sentido común, y la otra con la historia temprana de la República. Una tercera y satisfactoria opinión es la siguiente: - La Uncia fue la duodécima parte del as, y desde el pleno (12 oz.) la moneda de cobre todavía estaba en uso en Roma, cuando las Doce Tablas se convirtieron en ley, la frase fenus unciarium sería una expresión natural de interés de una sola onza en la libra; es decir, una duodécima parte de la suma prestada, o $8 \frac{1}{3}$ por ciento, no por mes, sino al año. Esta tasa, si se calcula para el año de duración romana de diez meses, daría un 10 por ciento para el año civil de los doce meses,

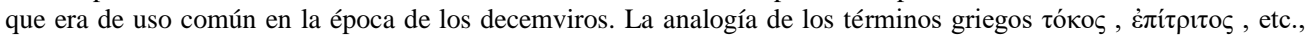
confirma este punto de vista, que, como observa Niebuhr, no queda invalidada por la admisión, que supone un pago anual y no mensual de interés.; pues aunque en los últimos tiempos de la República los intereses vencían todos los meses, no hay rastro de esta habiendo sido el caso anteriormente (Rein, Römische Privatrecht, P304). Tampoco es difícil dar cuenta de los cambios; probablemente estaba relacionado con las modificaciones realizadas de vez en cuando en la ley romana de deudor y acreedor (como la abolición de la esclavitud personal para la deuda), el efecto natural de lo que sería para hacer acreedores más escrupulosos en el préstamo de dinero, y mucho más vigilantes en la exigente debido al interés en ella. Herrera Bravo, R, Usurae. Ob., cit., pp.38 y ss.

21 Tito Livio, Ab Urbe condita, VI. 35 y 39. En VI.35.4. relata que los tribunos de la plebe Gayo Licinio y Lucio Sextio, hicieron públicos unos proyectos de ley dirigidos en contra del poder de los patricios y a favor de los intereses de la plebe. Uno de ellos que trataba sobre deudas disponía que la usura pagada se imputara a la disminución del capital y que los deudores pudieran satisfacer sus créditos en tres plazos anuales. En 6, 39, 2 deja constancia de hasta qué punto el proyecto sobre la represión de la usura era del agrado de la plebe. 
fijado por las XII Tablas de una onza por as libral, 1/12, a media onza, 1/24 de capital, y permitió a los deudores fraccionar también el pago de la deuda. La Lex Genucia del año 342 aC $^{23}$ prohibió para el territorio de Roma - no para el latino- el préstamo con intereses, dado que en esos momentos la usura estaba muy difundida, y había que acabar con el problema. Si bien no lo consiguió, puesto que los romanos transmitían el crédito a un ciudadano latino, quien les abonaba los intereses para reclamar posteriormente los intereses y el principal al deudor ciudadano romano ${ }^{24}$. Ante esto se dictó una Lex Sempronia ${ }^{25}$, que extendió la Lex Genucia a los latinos y demás pueblos aliados con Roma. Una Lex Marcia del año 104 a.C ${ }^{26}$ concedió la

22 Tito Livio Ab Urbe Condita, VII. 16: "Haud aeque laeta patribus insequenti anno C. Marcio Cn. Manlio consulibus de unciario fenore a M. Duillio L. Menenio tribunis plebis rogatio est perlata; et plebs aliquanto eam cupidius sciuit". CORPET MM-VERGER \& PESSONNEAUX, Histoire romaine de Tite-Live, t. II, Paris, Garnier, 1904: “Les patriciens virent avec moins de joie, l'année suivante, sous le consulat de C. Marcius et de Cn. Manlius, les tribuns du peuple M. Duilius et L. Ménius présenter, sur l'intérêt à un pour cent, une loi que le peuple, au contraire, accueillit et adopta avec empressement".

${ }^{23}$ Tito Livio Ab urbe Condita, en concreto, VII, 42, 1 refiere que en el año 192 a. C. se sustanciaron muchos pleitos contra los usureros, y duda que esta lex se debiera al tribuno Genucio. Praeter haec inuenio apud quosdam L. Genucium tribunum plebis tulisse ad plebem ne fenerare liceret ... CORPET MM -VERGER \& PESSONNEAUX, Histoire romaine de Tite-Live T.II, Paris, 1904: "Les patriciens virent avec moins de joie, l'année suivante, sous le consulat de C. Marcius et de Cn. Manlius, les tribuns du peuple M. Duilius et L. Ménius présenter, sur l'intérêt à un pour cent, une loi que le peuple, au contraire, accueillit et adopta avec empressement". Vid. POMA, G., "Il plebiscito Genucio ne fenerare licet (Liv VII.42.1)" en RSA 19(1989), pp., 73 y ss; FASCIONE, L., "La legislazione di Genucio", en F. Serrao (a cura di), Legge e società nella repubblica romana, II, Napoli, 2000, 179 ss., en particolar 182-185; CARDILLI, R., "Plebiscita et leges Antiusura. Leges fenebres, ius civile ed 'indebitamento' della plebe: a proposito di Tac. Ann. VI, 16, 1-2.” DIRITTO E STORIA nº7, 2008. http://www.dirittoestoria.it/7/Memorie/Cardilli-Plebiscita-legesantiusura.htm

Tácito, Annales, 6, 16 “...sane uetus urbi faenebre malum et seditionum discordiarumque creberrima causa eoque cohibebatur antiquis quoque et minus corruptis moribus. nam primo duodecim tabulis sanctum ne quis unciario faenore amplius exerceret, cum antea ex libidine locupletium agitaretur; dein rogatione tribunicia ad semuncias redactum, postremo uetita uersura. ...”; BURNOUF, JL, Oeuvres completes de Tacite, traduites en francais avec une introduction et des notes, Paris, 1859. “ ... L'usure fut de tout temps le fléau de cette ville, et une cause sans cesse renaissante de discordes et de séditions. Aussi, même dans des siècles où les mours étaient moins corrompues, on s'occupa de la combattre. Les Douze Tables réduisirent d'abord à un pour cent l'intérêt, qui, auparavant, n'avait de bornes que la cupidité des riches. Ensuite un tribun le fit encore diminuer de moitié ; enfin on défendit tout prêt à usure ..." CARDILLI, R : Plebiscita et leges Antiusura.ob., cit.

Appiano, Bellum civile, 1, 54 relata cómo en el año 91 a. C. la situación económica era especialmente difícil afectando particularmente a los propietarios de tierras, produciéndose numerosos conflictos entre acreedores y deudores al exigir aquellos los préstamos con intereses a pesar de que la Lex Genucia de federatione los prohibía e imponía castigos de tipo pecuniario a los que osaban infligirla. Vid. CAPONE, L, "Gli interventi edilizi nella repressione delle usurae", LABEO 45 (1999), pp., 193 y ss. FASCIONE, L., La legislazione di Genucio, Legge e socità nella Repubblica Romana 2. Napoli, 1988; PomA,G., "Il plebiscito Genucio ne fenerare liceret (Liv., VII, 42, 1)", en RSA 19., FASOLINO, F, Studi sulle Usurae, ob.,cit., p.25 sobre este pasaje de Appiano manifiesta que el historiador, a propósito de la muerte del pretor Aellio en el 89 a.C la reconduce al hecho de que el magistrado habría buscado dar eficacia a una antigua ley, inaplicada en la práctica, con la cual se prohibía el préstamo con intereses. En la página 26 el autor relata la discusión doctrinal existente sobre el plebiscito Genucio y su contenido que puede reconducirse a: a) los partidarios de que el contenido se refería a la prohibición total de los préstamos a interés. b) los partidarios de estimar que establecía con carácter excepcional una remisión total de los intereses sobre deudas ya existentes, dejando inalteradas las cosas para el futuro.

24 Tito Livio Ab urbe condita XXXV 7: "De ea re nihil temere decerni placuit; ad frequentiores consultatio dilata est. instabat enim cura alia, quod ciuitas faenore laborabat et quod, cum multis faenebribus legibus constricta auaritia esset, uia fraudis inita erat ut in socios, qui non tenerentur iis legibus, nomina transcriberent; ita libero faenore obruebantur debitores. cuius coercendi cum ratio quaereretur, diem finiri placuit Feralia quae proxime fuissent, ut qui post eam diem socii ciuibus Romanis credidissent pecunias profiterentur, et ex ea die pecuniae creditae quibus debitor uellet legibus ius creditori diceretur. inde postquam professionibus detecta est magnitudo aeris alieni per hanc fraudem contracti, M. Sempronius tribunus plebis ex auctoritate patrum plebem rogauit plebesque sciuit ut cum sociis ac nomine Latino creditae pecuniae ius idem quod cum ciuibus Romanis esset."

25 Di Lella, L, Il plebiscito Semproniano del 193 a.C e la repression delle "usurae", Atti dell Accademia di Scienze Morali e Politiche 95 (1984), pp. 277 nt 68 y 279.

${ }^{26}$ Gai 4.23: "Sed aliae leges ex quibusdam causis constituerunt quasdam actiones per manus iniectionem, sed puram, id est non pro iudicato, uelut lex Furia testamentaria aduersus eum, qui legatorum nomine mortisue causa plus $M$ 
Intereses de prestamos de dinero: limitaciones legales y efectos civiles de su abusividade em el Derecho Romano

manus iniectio contra los usureros. Sila propuso en el año 88 a.C la Lex Cornelia Pompeia de fenore $^{27}$, que reestableció la regulación de las XII Tablas-fenus unciarium.

Plutarco $20.3^{28}$ relata que en las provincias de Asia el procónsul Lucio Licinio Lucullo en los años 72-70 a.C estableció el límite máximo del interés en el 12\%, disponiendo también, que los intereses no debían superar el capital debido, y prohibiendo que el acreedor se apropiase de más del $25 \%$ de los bienes del deudor. Asimismo sancionó con la pérdida del crédito a quien añadiese intereses al capital prestado.

Cicerón, gobernador de Cilicia en el 51 a.C, reprodujo en el propio edicto provincial la normativa que afectaba a la centesima, estableciendo el límite del 12\% anual, pero permitió el anatocismo, que Lúculo había sancionado con la pérdida del crédito (Ad Att 5.21.13) ${ }^{29}$.

Esta normativa se extendió a Roma en el año 51 a.C, mediante un senadoconsulto ${ }^{30}$, que unificó el tipo máximo de interés al $12 \%$ anual (1\% mensual): Usurae centesimae ${ }^{31}$, que se mantendrá por Diocleciano (CJ 4.2.8) ${ }^{32}$ y Constantino (CTh 2.3.3.1) y hasta las reformas operadas por el derecho justinianeo. También se denominaban kalendariae, porque se cobraban los días primero de cada mes (kalendae), y generaban la actio kalendarii.

assibus cepisset, cum ea lege non esset exceptus, ut ei plus capere liceret; item lex Marcia aduersus faeneratores, ut si usuras exegissent, de his reddendis per manus iniectionem cum eis ageretur".

${ }^{27}$ Festus, 516 L (BRuns, C. G., Fontes, II, Tübingen, 1909, p. 43) “Unciaria lex appellari coepta est, quam L. Sulla et Q. Pompeius tulere, qua sanctum est, ut debitores decimam partem [sortem annuis usuris penderent]".

28 Plutarco, Lúculo 20.3. Vid Broughton, T- Robert S., The Magistrates of the Roman Republic II, New York 1952, 106 y ss, Solidoro MARUOTI, L., « Sulla disciplina degli interessi convenzionali nell età imperiale ». INDEX, 25(1997), pp. 179 y ss. TORRENT, A., Usurae supra legitimum modum: Del edicto de Lucullo a los Severos en Studi per Giovanni Nicosia VIII, Milano, 2007, pp. 259 y ss. GARCÍA GONZALEZ, J.M., "El préstamo y la Usura en el mediterraneo antiguo”, LUCENTUM, $\mathrm{N}^{\circ} 3,1984$, p.310 y ss: “(...) en cuanto al límite máximo \{́centessimae usurae, supra sortis summam, ultra alterum tantum) hay una corriente doctrinal que la sugiere importada de Egipto a fines de la época republicana, siguiendo un texto de Plutarco que atribuye a Lúculo, durante su gobernación, el límite del $12 \%$ al año (que sería el precedente de la centésima), y que, de Asia, habría sido traído luego a Roma (PLUTAR$C O$, Lúculo, 20). Diodoro Sículo también postula el origen egipcio de la tasa máxima, pero remitiéndolo al derecho antiguo, autóctono, de aquella región, durante el siglo VIII a. C'.

${ }^{29}$ Cic. Ad Att. 5.21.11: “(...) interim cum ego in edicto translaticio centesimas me observaturum haberem cum anatocismo aniversario (...) Pugliese, G., "Riflessioni sull'editto di Cicerone in Cilicia" en Synteleia Arangio Ruiz II, Napoli, 1964, pp. 982 ss; PEPPE, L, Note sull èditto di Cicerone in Cilicia”, en LABEO 37, 1991, pp 14 ss. TORRENT, A., "Usurae supra legitimum modum", ob., cit., pp. 259.

${ }^{30}$ Cic. Ad Att. 5.21 .13 (...) Cum senatus consultum modo factum sit, puto, postquam tu es profectus, in creditorum causa, ut centesimae perpetuo fenore ducerentur". Vid. MOMMSEN, T Romische Gechichte, 3, Leipzig, 1856, 537 ss; MARtini, R., Richerche in tema di editto provinciale, Milano, 1969; SOLIDOro MARUOTI, L., "Sulla disciplina degli interessi convenzionali nell età imperiale” en INDEX, 25 (1997), pp. 179 y ss; CERVENCA, G., v.Usura (Diritto romano) Enc.Dir. XIV, Milano, 1992, pp. 1127 e. FAsolino, F., Studi sulle Usurae, Salerno, 2006, pp 37 y ss, donde analiza los problemas que presenta este senadoconsulto sobre la validez general del mismo.

${ }^{31}$ Sobre la regulación de los intereses en la época republicana, ver. ROYER, J. P., "Le problème des dettes à la fin de la République romaine", en Revue historique de droit français et étranger, 45 (1967), pp. 191-240 y 407-450; CERVEnCA, G., Contributo allo studio delle "usurae” cd. Legati nel diritto romano, Milano, 1969. BARLOW, CH.T., Bankers, Moneylenders, and Interest Rates in the Roman Republic, Michigan, 1978; TILLI, G., "Postremo vetita versura", en BIDR, 86-87 (1984), pp.147-163; STORCHI MARINO, A., "Quinqueviri mensarii, Censo e debiti nel IV secolo", en ATHENAEUM, 81 (1993), pp. 213-250; RIVIERE, Y., "Les quadruplatores, la répression du jeu de l'usure, et de quelques autres délits sous la république romaine", en Mélanges d'archéologie et d'histoire de l'École Française de Rome, Antiquité, 109 (1997), pp. 577-631; SOLIDORO MARUOTI, L., « Sulla disciplina degli interessi convenzionali nell'età imperiale ». INDEX, 25 (1997), pp,179 y ss; PIKULSKA, A. "Problème de l'usure en Rome républicaine, favor debitoris?"en ORBIS IURIS ROMANI, 6 (2001), pp. 124-150.

${ }^{32}$ CJ 4.2.8 Imperatores Diocletianus, Maximianus. "Si pro mutua pecunia, quam a creditore poscebas, argentum vel iumenta vel alias species utriusque consensu aestimatas accepisti, dato auro pignori, licet ultra unam centesimam usuras stipulanti spopondisti, tamen sors, quae aestimatione partium placito definita est, et usurarum titulo legitima tantum recte petitur. Nec quicquam tibi prodesse potest, quod minoris esse pretii pignus quod dedisti proponis, quominus huius quantitatis solutioni pareas * DIOCL. ET MAXIM. AA. ET CC. PROCULO. *<A 293 S. XVII K. IAN. AA. CONSS. >" 
Constantino, en una constitución del año 325 d.C que nos transmite CTh $2.33 .1^{33}$, estableció un máximo del $50 \%$ en los préstamos en especies, y de un $12 \%$ anual en los préstamos de dinero ${ }^{34}$. Posteriormente, y debido a la introducción de la siliqua, que correspondía a 1/24 del solidus) los tipos de intereses se fijaron en la práctica en un 12,5\% -usura pseudocentesi$m a$ - por razones de cálculo ${ }^{35}$, que posteriormente adopta el Código de Eurico 285,936.

Estos límites máximos no significan que en los intereses pactados convencionalmente hubiera que llegar a ellos. La determinación del tipo de interés dependía del resto de elementos que se tenían en cuenta para la concesión de los préstamos: duración, liquidez del deudor, el objeto, etc.

En la edad republicana, Cicerón ep.5.6.2 37 da cuenta de buenos préstamos de larga duración garantizados, pactando intereses al 6\%. En la época imperial, eran comunes los acuerdos de intereses en porcentajes que oscilaban entre un 4 y $6 \%^{38}$. En cambio, los préstamos no garantizados, de breve duración, solicitados por personas de dudosa liquided, o en estado de necesidad, la tasa de interés convencional solía ser del $12 \%$ o más. A esta categoría pertenece la definida por Seneca como sanguinolenta centesima ${ }^{39}$.

${ }^{33}$ Cth 2.33.1: IMP. CONSTANT(INUS) A. AD DRACILIANUM AGENTEM VICES P(RAEFECTORUM) $\mathrm{P}(\mathrm{RAETORI}) \mathrm{O}$. Quicumque fruges humidas vel arentes indigentibus mutuas dederint, usurae nomine tertiam partem superfluam consequantur, id est ut, si summa crediti in duobus modiis fuerit, tertium modium amplius consequantur. Quod si conventus creditor propter commodum usurarum debitum recuperare noluerit, non solum usuris, sed etiam debiti quantitate privandus est. Quae lex ad solas pertinet fruges: nam pro pecunia ultra singulas centesimas creditor vetatur accipere. P(RO)P(OSITA) CAESAREA XV KAL. MAI. PAULINO ET IULIANO CONSS.

${ }^{34}$ Cth 2.33.1" (...) Quae lex ad solas pertinet fruges: Nam pro pecunia ultra singulas Centesimas creditor vetatur (vetetur gothofredus) accipere. Interpretatio. Nam quando pecunia fuerit commodata, nisi unam tantum centesimam a creditoribus exigi non iubemus". SOLIDORO MARUOTTI, L., "Sulla disciplina degli interessi convenzionali", ob.cit., p.186. n 27 donde indica que la derivación oriental de la medida del 50\% en la circunstancia de que Constantino emanó la constitución durante su residencia en Cesarea de Palestina, encargándosela a Draciliano, funcionario de Palestina en Egipto. Tal circunstancia indujo a pensar a Godofredo que la disposición tuviese vigor solamente en Palestina. Numerosas fuentes acreditan la difusión en todo el resto del Imperio.

35 BIANCHI, E., "In tema di usura. Canoni conciliari e legislazione imperiale del IV secolo del IV secolo. II.", en ATHENAEUM.62, 1984, pp., 142 y ss.

${ }^{36}$ D’ORs, A: El Código de Eurico. Estudios Visigoticos II, Madrid, 1960.p 207-208: “indica que los intereses no son exigibles si no figuran en la cautio (CE 285,3) o si el acreedor, aprovechándose de la necesidad del prestatario, estipuló unos intereses superiores a la tasa legal (CE 285,2), que se fija como la romana, corriente en la época post-Constantiniana, de la pseudo-centesima, es decir, la del 12,50 por 100 anual: tres siliquae por cada solidus o 1 solidus por cada 8. En la nota 682 aclara que cada solidus tenía 24 siliquae, remitiéndose a S. Isidoro, Etym 16.25.9. Leovigildo, para el mutuo de fruges, establece el interés del 50 por 100 (LV 5, 5, 9). Estas normas, aunque dentro siempre de la tradición romana, reflejan una nueva postura legislativa, congruente con la idea antes señalada como típicamente Euriciana del reparto del riesgo. Es de advertir todavía que la pérdida de todo interés cuando se han estipulado excesivos supone una cierta mitigación de la disciplina vigente, pues CTh 2,33,2(386) c. interp. Establece la pena del quadruplum de lo indebidamente cobrado, el duplum para los préstamos anteriores a la ley) y ETh 134 la de perder incluso el capital prestado- Amitat sortem debiti creditor qui ultra legitimam crediderit a debitore poscendum-; la norma Euriciana aparece así como una mitigación de la de Eth".

${ }^{37}$ Ciceron Epistula ad familiares a Publio Sextio 5.6., (...) partim mihi non credunt et a me insidias metuunt nec putant ei nummos deesse posse, qui ex obsidione feneratores exemerit.Omnino semissibus magna copia est; ego autem meis rebus gestis hoc sum assecutus, ut bonum nomen existimer.

${ }^{38}$ Pers. Sat 5.149 s (tasa del 5\%); colum de re r.3.3.9 (tasa del 6\%); Plinio. N.h. 14.4.6.56 (califica usura civilis ac modica la tasa del 6\%); Plin. Ep. 7.18 (tasa del 6\%). TORRENT, A: Usurae supra legitimum modum, ob., cit., p. 262 sostiene que "ciertamente nunca se aplicó con rigor este tipo del $12 \%$ anual elevado medio punto por Constantino (CTH 2.33.1.), en cuanto muchos textos dejan traslucir que no sólo había diferentes tasas de interés entre las distintas provincias sino también entre diversas civitates, de modo que por encima de eventuales rescriptos imperiales limitadores, el mos regiones (que obviamente traducía en términos económicos las necesidades de financiación en cada provincia) imponía diversos tipos válidos en las obligaciones convencionales en que ambas partes mediante stipulationes privadas fijaban el tipo de financiación".

${ }^{39}$ Seneca, De beneficiis 7,10: Quid sunt istae tabulae, quid computationes, et uenale tempus, et sanguinolentae centesimae? Solía recurrirse al mutuo con stipulatio en la praxis negocial. Vid. D.45.1.122.pr; D.12.1.40 y D.45.126.2. 
Intereses de prestamos de dinero: limitaciones legales y efectos civiles de su abusividade em el Derecho Romano

Justiniano inspirado en el principio del favor debitoris, ve la necesidad de reorganizar todo el régimen jurídico de la usurae, tanto la convencional como la legal, para lo cual dicta una serie de disposiciones normativas ${ }^{40}$. Comienza estimando necesaria hacer una ley para reducir los tipos de interés máximos, moderando los antiguos que producían una dura y pesadísima carga. Así en C 4.32.26.1, del 13 de diciembre del año 528 d.C ${ }^{41}$, estableció como tipo máximo general para los prestamos ordinarios entre particulares, el $6 \%$ anual- dimidia centesi$m a-$, con excepciones para las personas ilustres o las que les aventajan ${ }^{42}$, que no podían estipular intereses superiores al 4\% anual- minime licere ultra tertiam partem centesimae usurarum-; los banqueros y demás comerciantes profesionales al $8 \%$ anual $^{43}$, y los préstamos marítimos y de mercancías al $12 \%$ y $12 \frac{1}{2} \%$, anual, prohibiendo a los jueces aplicar las costumbres localesmos regiones: Nec liceat iudici memoratam augere taxationem occasione consuetudinis in regione obtinentis.

El 1 de abril del año 529 dicta una constitución imperial, dirigida a Menna, Prefecto del pretorio, recogida en CJ $4.32 .27^{44}$, en la que rechaza la mala interpretación que venían reali-

Los acreedores que intencionadamente pretendían exigir intereses en medida superior a la legalmente establecida por el ordenamiento jurídico, para no dejar ningún rastro de ello a fin de que el deudor no lo utilizase como prueba, solían acudir a un mecanismo- stipulationes sortis et usurarum- por el que el promisor se obligaba al pago sin distinguir lo debido a título de capital ni cuanto se debe a título de intereses. Al asumir el promisor una obligación abstracta, debía pagar la totalidad del objeto de la stipulatio.

${ }^{40}$ Sobre la legislación justinianea en tema de usurae ver, CAssimatis, G, Les intére 'ts dans la legislation de Justinien et dans le droit byzantin (Paris, 1931). BonINI, R: Richerche di diritto giustinianeo, Milano, 1968; BIANCHINI, G, La disciplina degli interessi convenzionali nella legislazione giustinianea . Studi in onore di A. Biscardi, II, Milano, 1982, pp. 393 y ss. LUCHETTI, G., « Banche, banchieri e contratti bancari nella legislazione giustinianea ».BIDR 94-95,1991-1992, pp. 450 y ss. FASOLINO, F., Studi sulle Usurae., ob., cit., p.160 indica que la constitución, cualificada como generalis sanctio por el mismo emperador, afronta de manera general y organizada la materia de los intereses; la nueva disciplina así emanada contempla por tanto diversos aspectos de la usurae, poniendo siempre el acento en la óptica de su contención

${ }^{41}$ CJ 4.32.26:1. Super usurarum vero quantitate etiam generalem sanctionem facere necessarium esse duximus, veterem duram et gravissimam earum molem ad mediocritatem deducentes. 2 . Ideoque iubemus illustribus quidem personis sive eas praecedentibus minime licere ultra tertiam partem centesimae usurarum in quocumque contractu vili vel maximo stipulari: illos vero, qui ergasteriis praesunt vel aliquam licitam negotiationem gerunt, usque ad bessem centesimae suam stipulationem moderari: in traiecticiis autem contractibus vel specierum fenori dationibus usque ad centesimam tantummodo licere stipulari nec eam excedere, licet veteribus legibus hoc erat concessum: ceteros autem omnes homines dimidiam tantummodo centesimae usurarum posse stipulari et eam quantitatem usurarum etiam in aliis omnibus casibus nullo modo ampliari, in quibus citra stipulationem usurae exigi solent. 3 . Nec liceat iudici memoratam augere taxationem occasione consuetudinis in regione obtinentis. IUST. A. MENAE PP. *<A 528 D. ID. DEC. CONSTANTINOPOLI IUSTINIANO PP A. II CONS.> HERRERA BRAVO, R, Usurae, ob., cit., pp 49 y ss afirma que se la c. 26 se califica como una generalis sanctio, proveyendo junto al límite máximo del $6 \%$ otra serie de tipos más bajos o un poco mas altos al tipo fijado.

${ }^{42}$ Solidoro Maruoti, L, "Sulla disciplina degli interessi convenzionalii”, ob. cit., pp. 558 y ss; FASOLINO, F., Studi sulle usurae, ob. cit., pp 168-169.

${ }^{43}$ FASOLINO, F., Studi sulle usurae, ob. cit., pp 169 ss. donde destaca que el fundamento de esta excepción establecida para los banqueros se encontraba en la presión de las reclamaciones efectuadas por las potentes corporaciones de argentarii, categoría en favor de la cual, les fueron concedidos beneficios sustanciosos, basta pensar en la novela 136.4 del 6 de febrero de 535, con la cual los banqueros obtenían la extensión de la tasa más elevada a los intereses derivados de pactos verbales, evidentemente frecuentes en el ámbito de su actividad; también en Ed 9.6.pr el emperador concede a los argentarii aplicar la tasa mas elevada en el caso que hubiere conseguido una milicia o hubieren devenido ilustres, derogando cuanto había establecido poco antes con relación a esta categoría social en CI 4.32.26.2. A este autor no le parece de todo exacto esta hipótesis pues también piensa que Justiniano tuvo en cuenta la necesidad de preveer una adecuada forma de remuneración para los que profesionalmente se dedicasen a la actividad de préstamos con interés. Reducir el margen de ganancia de los banqueros habría significado desincentivarles de continuar invirtiendo los capitales en financiación que se revela necesaria para las inversiones productivas y comerciales y para garantizar un determinado nivel mínimo de consumo. Por otro lado, la opinión tradicional parece excesivamente centrada en la consideración solo de los argentarii, olvidando el dato que la tasa del $8 \%$ se extendía a todas las categorías de empresarios.

${ }^{44}$ CJ 4.32.27. Imperator Justinianus. De usuris, quarum modum iam statuimus, pravam quorundam interpretationem penitus removentes iubemus etiam eos, qui ante eandem sanctionem ampliores quam statutae sunt usuras stipulati 
zando algunos sobra la tasa de intereses que había establecido, y ordena que los que habían estipulado intereses mayores a la tasa legal, debían ajustar sus acciones a la cuantía tasada en la misma ley desde el tiempo de su promulgación, habiendo de exigir los intereses del tiempo transcurrido hasta su promulgación conforme al tenor de la estipulación. Asimismo, reafirmó la antigua prohibición de las usurae supra duplum, no concediendo de ninguna manera que los intereses superen en más del doble el capital prestado, extendiendo dicha prohibición también a los juicios de buena fe así como en todos los demás casos en que se exijan intereses.

En la Novela $121.2^{45}$ del año 542 d.C, el emperador Justiniano, en relación con la prohibición de exigir usurae supra duplum, dispone que lo intereses ya pagados serán imputados al capital, o estando obligado el deudor a restituir el capital -sors- cuando hubiere abonado al acreedor, a título de intereses, una suma igual al doble de la suma prestada. Asimismo, abole de forma expresa un rescripto del emperador Caracalla, de contenido opuesto, que nos transmite CJ $4.32 .10^{46}$, de tal forma que los intereses pagados por plazos sí le aprovechan al deudor, a los fines de respetar el límite del duplum. ${ }^{47}$

Basilio Macedonio en el siglo IX prohibió la usura, pero su hijo Leon VI el filósofo revocó la prohibición permitiendo unos intereses del $4 \%$ tal como se nos trasmite en la constitución 83 del emperador León a Stiliano ${ }^{48}$, al estimar que a causa de la pobreza, la prohibición de los intereses establecida por su padre, no redunda en mejoría, que era el propósito del legislador, sino en empeoramiento, porque después de promulgada la ley, quienes antes entregaban dinero en mutuo, al no poder percibir ningún lucro del mutuo, son inhumanos y crueles contra los que necesitan de tal humanidad de recibir dinero a préstamo. Siendo por ello que dicta una nueva constitución, en la que dispone que el uso del mutuo produzca intereses al $4 \%$, por lo que cada año produce para los prestamistas una silicua cada sueldo.

La tasa usual en época justinianea, no obstante, era del $6 \%$ anual con carácter general para los préstamos ordinarios entre particulares, salvo el préstamo marítimo, que por su propia naturaleza soportaba la imposición de tasas superiores, sin olvidar que los prestamos de los banqueros y demás comerciantes profesionales estaban fijadas en el $8 \%$ anual.

sunt, ad modum eadem sanctione taxatum ex tempore lationis eius suas moderari actiones, illius scilicet temporis, quod ante eandem fluxit legem, pro tenore stipulationis usuras exacturos. 1. Cursum insuper usurarum ultra duplum minime procedere concedimus, nec si pignora quaedam pro debito creditori data sint, quorum occasione quaedam veteres leges et ultra duplum usuras exigi permittebant. 2. Quod et in bonae fidei iudiciis ceterisque omnibus in quibus usurae exiguntur servari censemus. * IUST. A. MENAE PP. *<A 529 D. K. APRIL. CONSTANTINOPOLI DECIO VC. CONS.>

${ }^{45}$ NJ 121.2: Itaque quoniam leges nostrae nihil supra duplum solvi volunt, eamque a prioribus discrepantiam habent, quod illae quidem debita usque ad duplum sistebant, si nulla solutio facta esset, nos autem eas quoque solutiones quae per partes fiant debita solvere permisimus, siquidem usque ad duplum perveniant, sancimus ut secundum hoc fiat computatio, atque illi si quantum reliqui sit ad mille aureos solvant etiam feneraticiam sescentorum aureorum cautionem recipiant, ne ex hac causa eveniat ut multiplicatum debitum exigatur. Epilogus. Magnificentia igitur tua quae nobis placuerunt et per hanc sacram pragmaticam sanctionem declarantur ad opus et effectum adducere studeat, ut et interpretatio contra haec prolata in sententiis, quarum supplices meminerunt, abiciatur, et omnia quae per obreptionem et ab una parte adversus legem acta sunt vel agentur cessent. Divinitas te servet per multos annos, frater iucundissime. Dat. XVII. k. Mai. CP. Belisario vc. cons.

${ }^{46}$ CJ 4.32.10 Imperator Antoninus. Usurae per tempora solutae non proficiunt ad dupli computationem. Tunc enim ultra sortis summam usurae non exiguntur, quotiens tempore solutionis summa usurarum excedit eam computationem * ANT. A. CRATO ET DONATO MIL.

${ }^{47}$ Vid NJ 138 Imp. Iustinianus pp. Aug. Hermogeni magistro officiorum. Manifestissima est nostri numinis constitutio, quae usque ad dupli quantitatem exactionem debiti concludit Si igitur creditores tui quidam in duplum acceperunt, alii adhuc minus consecuti sunt, hi quidem qui in duplum ex usurarum quantitate per diversa tempora consecuti sunt, nullam adversus te inquietudinem proponere concedantur, alii autem, si simili modo repleti fuerint, eo modo silere conpellantur; et si debita sua consecuti fuerint, feneraticias cautiones recuperari, vel si remanserint, suis viribus vacare, si preces verae sunt, praesentis oraculi sanctione decernimus.

${ }^{48}$ Novela del emperador Leon a Styliano, constitución 83 
Intereses de prestamos de dinero: limitaciones legales y efectos civiles de su abusividade em el Derecho Romano

\section{CONSECUENCIAS CIVILES DE ACORDAR/PACTAR INTERESES ILEGÍTIMOS}

En el derecho romano se preveían consecuencias penales ${ }^{49}$ y civiles para aquellos acreedores que exigían ilegítimamente intereses. En el presente trabajo únicamente voy a destacar las consecuencias civiles que preveía el ordenamiento jurídico romano en estos supuestos, que afectaban tanto al derecho del acreedor como al resarcimiento del deudor.

\subsection{Consecuencias que afectan al derecho de crédito del acreedor}

El ordenamiento jurídico romano negaba al acreedor acciones para reclamar intereses que superasen la tasa legal: denegatio actionis.

La sanción establecida en estos supuestos consistía en la imposibilidad de ser exigidos. Los intereses ilícitos se tenían por no expresados o no puestos. Así se manifiesta Ulpiano, comentario al edicto, Libro XXVI, contenido en D. 12.6.26.1, donde se afirma que no pueden comprenderse en la estipulación, ni exigirse los intereses sobre el duplo: supra duplum autem usurae et usurarum usurae nec in stipulatum deduci, nec exigi possunt $(\ldots)^{50}$.

Paulo en sus comentarios a Sabino, Libro XII recogidos en D.22.1.2051, deja claro que los intereses ilícitos, mezclados con el capital, no vician el capital y por tanto no se deben: Usuras illicitas sorti mixtas ipsas tantum non deberi constat, ceterum sortem non vitiare.

Marciano en el comentario a la Instituta, libro XIV, que nos transmite D. 22.1.2952, relata que se determinó - placuit-, que si alguno hubiere estipulado o intereses sobre la tasa estable-

49 GLÜCK, F, Commentario alle Pandette, ob. cit., pp., 106 y ss. Rotondi G., Vecchie e nuove tendenze per la repressione dell 'usura. Scritti giuridici III. Milano 1922. SOLIDORO MARUOTI, L, "Sulla disciplina degli interessi convenzionale nell 'età imperiale", INDEX 25 (1997), pp. 203 y ss., SALAZAR REVUELTA, M., "La represión penal de la usura en la república romana y su evolución". REVISTA ESTUDIOS HISTORICO-JURIDICOS. n. 26, Valparaíso 2004, pp. 85111. Idem: Les sanctions pénales des usurae illicitae dans les codes romains des periodes post-classique et byzantine et leurs antécédents historiques. Doctrine et practiques pénales en Europe. Montpellier, 2011, pp.45 y ss.

${ }^{50}$ D. 12.6.26.1, Ulpianus libro 26 ad edictum: Supra duplum autem usurae et usurarum usurae nec in stipulatum deduci nec exigi possunt et solutae repetuntur, quemadmodum futurarum usurarum usurae. CERVENCA, G, "Sul divieto delle cd. "usurae supraduplum"”, INDEX 2 (1971) 291 y ss. Id. Sv Usura (diritto romano) en ED, 45, Milano 1992, 1128. SOLIDORO MARUOTTI, L, "Ultra sortis summam usurae non exiguntur" en LABEO 28 (1982), 164 y ss; y en "Sulla disciplina degli interessi convenzionale nell'età imperiale", INDEX 25 (1997) 179 y ss.

${ }^{51}$ D.22.1.20 Paulus, libro 12 ad Sabinum: "Usuras illicitas sorti mixtas ipsas tantum non deberi constat, ceterum sortem non vitiare". SOLIDORO MARUOTTI, L, "Sulla disciplina degli interessi convenzionale", ob., cit., p. 201, destaca que el pasaje tiene un enunciado de carácter general. Se pueden convenir intereses excediendo de la tasa consentida sin que por esto resulte afectada la totalidad del contrato. Sin embargo, no está claro si Paulo mantiene exigible solamente la sors (y la formulación del texto haría pausible esta hipótesis), o, de conformidad, con la solución precedentemente expuesta, también podrían exigirse los límites legales. Si una disputa jurisprudencial realmente existió, ella desapareció con una constitución emanada en el año 239, con la cual se precisó, que en presencia de una estipulación que tenía por objeto usurae ilícitas, el deudor estaba obligado a pagar ya el capital, ya los intereses en la medida de la centesima".

52 D. 22.1.29 Marcianus libro 14 institutionum: "Placuit, sive supra statutum modum quis usuras stipulatus fuerit sive usurarum usuras, quod illicite adiectum est pro non adiecto haberi et licitas peti posse". Vid. MURILLO VILLAR, A, Anatocismo. Historia de una prohibición. Homenaje a JL. Murga, Madrid 1994, pp. 504 y 505. FASOLINO, F: Studi sulle usurae, ob.cit., pp. 56 y ss. quien afirma que el fragmento, de cuya clasicidad no puede dudarse expone coherentemente con la naturaleza institucional de la obra de la cual ee un experto, un evidente principio general, casi seguramente introducido, como se resalta con la expresión placuit, por constituciones imperiales que, sin embargo, no vienen expresamente mencionadas. Un sector de la doctrina, ha sostenido la alteración del fragmento, al estimar que solo en la edad postclásica o justinianea existía la posibilidad de reducir los efectos negociales por medio de la invalidez parcial. Vid. PARTSCH, J, Die Lehre vom Scheingeschäfte im römischen Rechte, ZSS 42 (1921) p. 266., nt 1; Cugia, S, La nullità parziale del negozio giuridico nel D.24.1, Napoli 1922; BETTI, E, Diritto romano, Padova 
cida, sive supra statutum modum uis usuras stipulatus fuerit, o intereses de los intereses, sive usurarum usuras, se tenga por no expresado lo que ilícitamente se expresó, quos illicite adiectum est, pro non adiecto haberi, y que se puedan pedir los lícitos: et licitas peti posse.

En consecuencia, estimaban que el contrato de préstamo era válido y eficaz y también el acuerdo, en virtud del cual el préstamo producía intereses; si bien la cuantía de los intereses no podía superar la tasa legal establecida, de tal forma que si la superaba, el acreedor únicamente podía reclamar la cuantía que se ajustase a los límites de la tasa legal, teniendo por no puesto lo añadido ilícitamente. La disciplina clásica preveía, en consecuencia, la invalidez parcial de la estipulación que tenía por objeto intereses que excedían de los límites fijados normativamen$\mathrm{te}^{53}$.

El deudor únicamente ha de pagar el capital debido y los intereses lícitamente acordados, reduciéndose los que superen la cuantía ex officio iudicis ${ }^{54}$, tal como refiere Paulo en un comentario del liber singularis de usuris, recogido en D. 22.1.17 Pr., en el que reproduce un rescripto de Marco Aurelio: divus Marcus fortunato ita rescripsit: "Praesidem provinciae adi, qui stipulationem, de cuius iniquitate questus est, ad modum iustae exactionis rediget".

Esta regla fue sancionada legalmente en una constitución de Diocleciano del año 293 d.C., recogida en CJ $4.2 .8^{55}$, que proclama que solamente se pide con derecho el capital que se fijó en la estimación por convenio entre las partes, y a título de intereses el importe legal: et usurarum titulo legitima summa tantum recte petitur.

Constantino, en una constitución reproducida en CTh 2.33.1 ${ }^{56}$, establece que el acreedor sufrirá la pérdida no solo de los intereses, sino también del capital. Esta sanción se reproduce posteriormente en la Lex Romana Burgundionum $31.4^{57}$, y en el Edicto de Teodorico $134^{58}$.

Justiniano niega la tutela jurisdiccional al acreedor que quiera exigir intereses superiores a la tasa legal -inexigibilidad de intereses así pactados-, disponiendo que los intereses ya pagados disminuyan en esta cantidad la deuda principal -el capital-, prohibiendo que se exija tanto

1935, pp. 333 y 343. SOLIDORO MARUOTI, L, Ultra sortis summam usurae non exiguntur, Labeo 28, p.170. Idem en "Sulla disciplina degli interessi convenzionali" cit., p.200.

53 Invalidez parcial que también se observa en D. 22.1.9.pr Papinianus libro 11 responsorum" Pecuniae faenebris, intra diem certum debito non soluto, dupli stipulatum in altero tanto supra modum legitimae usurae respondi non tenere: quare pro modo cuiuscumque temporis superfluo detracto stipulatio vires habebit" y en D.22.1.20 Paulus, libro 12 ad sabinum, vid n. 70. Vid. TORRENT, A. Usurae supra legitimum modum, ob., cit., p.282. DOMINGUEZ TRISTAN, P., "La nulidad parcial en el derecho contractual europeo", ob., cit.

${ }^{54}$ SOLIDORO MARUOTI, L "Sulla disciplina degli interessi convenzionali”., ob., cit., pp. 200-201.

${ }^{55}$ CJ 4.2.8 Imperatores Diocletianus, Maximianus. Si pro mutua pecunia, quam a creditore poscebas, argentum vel iumenta vel alias species utriusque consensu aestimatas accepisti, dato auro pignori, licet ultra unam centesimam usuras stipulanti spopondisti, tamen sors, quae aestimatione partium placito definita est, et usurarum titulo legitima tantum recte petitur. Nec quicquam tibi prodesse potest, quod minoris esse pretii pignus quod dedisti proponis, quominus huius quantitatis solutioni pareas * DIOCL. ET MAXIM. AA. ET CC. PROCULO. *<A 293 S. XVII K. IAN. AA. CONSS. Vid. SOLIDORO MARUOTI, L, "Sulla disciplina degli interessi convenzionali”., ob., cit., p. 201 y nota 62 y 202.

${ }^{56}$ CTh. 2.33.1 : IMP. CONSTANT(INUS) A. AD DRACILIANUM AGENTEM VICES P(RAEFECTORUM) $P($ RAETORI)O. Quicumque fruges humidas vel arentes indigentibus mutuas dederint, usurae nomine tertiam partem superfluam consequantur, id est ut, si summa crediti in duobus modiis fuerit, tertium modium amplius consequantur. Quod si conventus creditor propter commodum usurarum debitum recuperare noluerit, non solum usuris, sed etiam debiti quantitate privandus est. Quae lex ad solas pertinet fruges: nam pro pecunia ultra singulas centesimas creditor vetatur accipere. P(RO)P(OSITA) CAESAREA XV KAL. MAI. PAULINO ET IULIANO CONSS. Vid. SOLIDORO MARUOTTI, L., "Sulla disciplina degli interessi convenzionali"., ob., cit., p. 205.

${ }^{57}$ LRB 31.4: Si quis duas centesimas pro cautione sibi stipulari fecerit aut fieri pertulerit, etiam eius pecunie, quam praestetit, amissione multabitur secundum legem Theudosiani: de usuris.

${ }^{58}$ Edicto de Teodorico 134: Qui ultra legitimam centesimam a debitore suo speraverit. Amittat sortem debiti creditor, qui ultra legitimam centesimam crediderit a debitore poscendum. [CTh. 2, 33, 2). 
Intereses de prestamos de dinero: limitaciones legales y efectos civiles de su abusividade em el Derecho Romano

esta parte que ha de disminuirse desde un principio, como los intereses de la misma y así lo dispone en una constitución dada en Constantinopla el año 528 d.C contenida en CJ 4.32.26.1 ${ }^{59}$ y en la Novela $121^{60}$ del año 542 d.C.

En la práctica, la constitución recogida en CJ 4.32.26.1 se consideraba aplicable solo a futuros pactos de intereses, celebrados tras la entrada en vigor de dicha disposición. Pero esa no habría sido la intención de Justiniano, quien para evitar estas malas interpretaciones, promulgó una nueva constitución, en las calendas de abril del año 529 d.C a la que se refiere CJ 4.32.27.pr., ${ }^{61}$ en la que dejando claro su rechazo a esas interpretaciones, dispuso que los que antes de esta ley estipularon intereses mayores a los que se fijaron, deben ajustar sus acciones a la cuantía tasada en la misma ley desde el tiempo de su promulgación, habiendo de exigir los intereses del tiempo que transcurrió antes de la misma ley conforme al tenor de la estipulación. Es decir, dispuso una parcial eficacia retroactiva a lo establecido en la constitución recogida en CJ 4.32.26.1 para todos los pactos anteriores al 13 de diciembre del año 528.

El emperador no habla de declarar previamente la nulidad de las estipulaciones, o acuerdos relativos a los intereses en medida superior a la establecida. FASOLINO ${ }^{62}$ afirma que se entiende implícita en virtud de lo sancionado por Novela Teodosiana 9, del año 439, sobre la base de la cual se declaraba la ineficacia y la inexistencia de todos los actos contrarios a prohibiciones normativas, ante la ausencia de una explicita previsión en tal sentido por parte del legislador: Nullum enim pactum, nullam conventionem, nullum contractum inter eos videri volumus subsecutum, qui contrahunt lege contrahere prohibente.

Como puede observarse, impera mayoritariamente en las fuentes romanas la técnica conservadora de los negocios jurídicos, de forma que la nulidad de la estipulación es parcial, en aplicación de la regla utile per inutile non vitiatur ${ }^{63}$.

SOLIDORO $^{64}$, refiriéndose al aspecto procesal de la cuestión, destaca que la protección del deudor se arbitraba mediante la denegatio actionis del magistrado, por manifiesta iniquidad de la intentio, o concediendo una exceptio al demandado para oponerse a la pretensión del acreedor, destacando las diferencias entre ambos mecanismos procesales, pues la denegatio actionis no impedía que la acción pudiera ser ejercitada ante otro magistrado, mientras que la concesión de la exceptio al deudor, conllevaba el efecto extintivo de la acción que producía la litis contestatio, de tal forma que el acreedor no podía volver a reproducir su pretensión ante otro magistrado.

${ }^{59}$ CJ 4.32.26.1 “ Super usurarum vero quantitate etiam generalem sanctionem facere necessarium esse duximus, veterem duram et gravissimam earum molem ad mediocritatem deducentes".

${ }^{60} \mathrm{~N} 121$ (...) ne ex hac causa eveniat ut multiplicatum debitum exigatur.

${ }^{61}$ CJ 4.32.27, Pr.: Imperator Justinianus. De usuris, quarum modum iam statuimus, pravam quorundam interpretationem penitus removentes iubemus etiam eos, qui ante eandem sanctionem ampliores quam statutae sunt usuras stipulati sunt, ad modum eadem sanctione taxatum ex tempore lationis eius suas moderari actiones, illius scilicet temporis, quod ante eandem fluxit legem, pro tenore stipulationis usuras exacturos. IUST. A. MENAE PP. *<A 529 D. K. APRIL. CONSTANTINOPOLI DECIO VC. CONS.>

${ }^{62}$ FASOLINO, F., Studi sulle usurae., ob.,cit., pp.178-179

${ }^{63}$ D. 45.1.1.5 Ulpianus libro 48 ad Sabinum: "Sed si mihi Pamphilum stipulanti tu Pamphilum et Stichum spoponderis, Stichi adiectionem pro supervacuo habendam puto: nam si tot sunt stipulationes, quot corpora, duae sunt quodammodo stipulationes, una utilis, alia inutilis, neque vitiatur utilis per hanc inutilem".

${ }^{64}$ Solidoro Maruoti, L., "Sulla disciplina degli interessi convenzionali"., ob. cit., p.202-203 y la nota 64 donde se cita bibliografía sobre la relación denegatio actionis y exceptio. 


\subsection{Resarcimiento del deudor}

¿Qué medios confería el ordenamiento jurídico romano, para que el deudor obtuviese el resarcimiento de los intereses que hubiera pagado por encima de la tasa legal?. En el Derecho romano se distinguían dos supuestos según que el capital aun no hubiera sido devuelto íntegramente al acreedor, o sí se hubiera pagado íntegramente, habiéndose extinguido la obligación por pago.

\subsubsection{Si el capital no se había pagado íntegramente}

El ordenamiento jurídico romano optó por la solución de aplicarlos al capital, no pudiendo ser repetidos.

Tito Livio, Ab Urbe condita, VI.35.4 $4^{65}$ relata que los tribunos de la plebe Gayo Licinio y Lucio Sexto, hicieron públicos unos proyectos de ley dirigidos en contra del poder de los patricios, y a favor de los intereses de la plebe. En uno de ellos disponía, que la usura pagada se imputara a la disminución del capital, y que los deudores pudieran satisfacer sus créditos en tres plazos anuales.

Ulpiano, en los comentarios al Edicto, libro XXVI, contenido en D.12.6.26.pr ${ }^{66}$ contesta apelando a un rescripto del Divino Severo -quo iure utimur-, que no pueden ser repetidos: repeti quidem non posse, sino que han de ser aplicados al capital -sed sorti imputandum. Si después pagó el capital, puede repetirse el capital, como no debido: et si postea sortem solvit, sortem quasi indebitum repeti posse.

Tal principio también se reproduce en las Sentencias de Paulo 2.14.267 Usurae supra centesimam solutae sortem minuunt, consumpta sorte repeti possunt. De tal forma, que solamente los intereses pagados por encima de la centesima deben imputarse al capital, pudiendo recuperar el exceso pagado a título de intereses, mediante el ejercicio de la condictio indebiti, cuando se hubiere pagado el capital.

A diferencia de las anteriores consecuencias que nos transmiten los juristas romanos, la Novela Teodosiana 9 del año 439 d.C. dispone que todos los actos contrarios a prohibiciones, normativamente impuestas, se sancionan con ineficacia e inexistencia, aunque faltase una explicita disposición legal en tal sentido, bien pudiendo la prohibición derivar de una lex imper-

65 Tito Livio, Ab urbe condita, VI.35.4 (...) “ creatique tribuni C. Licinius et L. Sextius promulgavere leges omnes adversus opes patriciorum et pro commodis plebis: unam de aere alieno, ut deducto eo de capite quod usuris pernumeratum esset id quod superesset triennio aequis portionibus persolveretur".

${ }^{66}$ D. 12.6.26.pr: "Si non sortem quis, sed usuras indebitas solvit, repetere non poterit, si sortis debitae solvit: sed si supra legitimum modum solvit, divus Severus rescripsit (quo iure utimur) repeti quidem non posse, sed sorti imputandum et, si postea sortem solvit, sortem quasi indebitam repeti posse. Proinde et si ante sors fuerit soluta, usurae supra legitimum modum solutae quasi sors indebita repetuntur. Quid si simul solverit? Poterit dici et tunc repetitionem locum habere". Vid. FASOLINO, F, Studi sulle usurae, pp.41 y ss. TORRENT, A: Usurae supra legitimum modum, ob., cit., n.49 en la que indica que en la reconstrucción del edicto suena asi: "Nunc videndum de indebito soluto. Et quidem si quis indebitum ignorans solvit, per hanc actionem condicere potest:sed et si sciens se non debere solvit, cessat repetitio". Igualmente ver la situación económica que existía en esa época y que relata el profesor Torrent en las páginas 266 y ss.

${ }^{67}$ Pauli sententiarum interpretatio 2.14.2. In pecuniis creditis cum solutio usurarum sortem aequaverit, si quid amplius creditori fuerit datum, de capite debiti subtrahitur. Si vero et centesima et caput impletum est, quod amplius creditor accepit, reddere cogetur debitori. Vid. TORRENT, A, Diccionario de derecho romano, ob., cit., pp. 360 y 361. 
Intereses de prestamos de dinero: limitaciones legales y efectos civiles de su abusividade em el Derecho Romano

fecta,o de un senadoconsulto, por lo tanto no sería idóneo para provocar la rescisión del acto viciado.

Justiniano en CJ 4.32.26.1 $1^{68}$ dispone que los intereses recibidos por el acreedor contra la tasa establecida en ésta constitución, obligatoriamente han de aplicarse al capital, disminuyendo en esta cantidad la deuda principal, sin que el acreedor tenga facultad para deducir o retener alguna cosa por razón de silicua, o espórtulas o de cualquier otra causa, de las cantidades que se hayan de dar a interés.

Sentado lo anterior, una cuestión a resolver afecta a la forma en que se imputarán al capital los intereses pagados contra la tasa establecida.

LEYSER $^{69}$ señala dos formas de efectuar la imputación:

1) La primera consiste en deducir cada año del capital lo pagado de más de la tasa lícita de intereses, de modo que cada año se reduce el superávit del capital.

2) La segunda consiste en dejar intacto el capital, hasta que sea pagado, y luego restar en bloque el superávit pagado en intereses, como una única suma del capital.

A primera vista puede observarse que ambos modos de cómputo son muy diferentes y que el primero resulta más gravoso al acreedor que el segundo. En efecto para este autor, con el primer modo el capital puede ser cancelado por el exceso de intereses pagados por encima de la tasa lícita; mientras que con el segundo no será tan fácil. Según LEYSER, la primera forma de realizar el cómputo debería tener lugar si el acreedor demanda para obtener el capital, a continuación, se opone la excepción derivada de los intereses pagados por encima de la tasa lícita. El segundo cómputo debe tener lugar si el deudor, después de que ya ha pagado la capital, repite con una condictio los intereses pagados por encima de la tasa legal.

WINCKLER $^{70}$, MÜLLER ${ }^{71}$ niegan que los intereses pagados ilegítimamente disminuyan ipso iure el capital; se concederá al deudor solo la facultad de deducir del capital el superávit pagado en intereses; mas este superávit lo consideran como un capital especial, sobre el cual el acreedor debe pagar por todos los años, que disfrutaron del capital, los intereses.

Otro sector doctrinal, encabezado por BAUER ${ }^{72}$, opina que los intereses pagados en exceso disminuyen ipso iure el capital en el momento del pago. Esta idea se ajusta a la naturaleza de la compensación. El capital de año en año, motivado por los intereses pagados de más progresivamente, va disminuyendo, y finalmente desaparecerá totalmente. El acreedor debe tolerar este efecto de la compensación, por cuanto al aceptar los intereses ilícitos, él mismo lo ha provocado.

\footnotetext{
${ }^{68}$ CJ 4.32.26.1: (...)"Si quis autem aliquid contra modum huius fecerit constitutionis, nullam penitus de superfluo habeat actionem, sed et si acceperit, in sortem hoc imputare compelletur, interdicta licentia creditoribus ex pecuniis fenori dandis aliquid detrahere vel retinere siliquarum vel sportularum vel alterius cuiuscumque causae gratia. Nam si quid huiusmodi factum fuerit, principale debitum ab initio ea quantitate minuetur, ut tam ipsa minuenda pars quam usurae eius exigi prohibeantur".

${ }^{69}$ LeYSER., A Von, Meditationes ad Pandectas, Vol IV, editio nova, Gegel 1778. Specimen CCXL, 10, pp. 879 y ss.

70 WINCKLER, K. G. VON, De condictione immodici foeneris, Lipsiae 1765.

71 MÜLler, Observation pract. ad Leyserum, T.III citado por GLÜCK, F, Commentario alle pandette, traducido por Filippo Serafini, L.XXII, Milano, 1906, p.104, n.80.

72 BAUER, JG, De usuris sorti imputandis vel repetendis, Lipsiae, 1760.
} 


\subsubsection{Si el capital ya había sido pagado}

El deudor puede reclamar los intereses recibido por el acreedor por encima de la tasa lícita, por medio de la condictio. C.4.32.18 ${ }^{73}$.

$\mathrm{CUJACIO}^{74}$, analizando el texto de las Sentencias de Paulo 2.14, indica que las usurae que exceden de la centesima, per errorem solutae repeti possunt.

Para GLUCK ${ }^{75}$, se trata de una condictio sine causa, mas que una condictio indebiti, pues estima que en este caso no se puede admitir un error por parte del deudor, ni por parte del acreedor, y como los intereses una vez pagados han perdido la cualidad de intereses, así esta claro por qué para los juristas romanos el superávit de los intereses no podían ser reclamados como intereses, sino como capital restituido, tal como se observa en D. 12.6.26. pr.

\section{Conclusion}

Estas soluciones propuestas por el derecho romano, están de plena aplicación en el derecho español vigente.

En la práctica jurídica española, cuando los tribunales españoles se enfrenten a estos problemas derivados de la exigibilidad del crédito por parte de un acreedor, que pretenda exigir intereses derivados de las llamadas cláusula suelo, podrían aplicar las siguientes soluciones:

A) Inadmitir a tramite la demanda: denegatio actionis, al contener reclamación de intereses derivados de una clausula que ha de tenerse por no puesta, por aplicación del articulo 6 de la Directiva 93/13/CEE del Consejo, de 5 de abril de 1993, sobre las cláusulas abusivas en los contratos celebrados con consumidores, y del articulo 83 del TRLGCYU, y tal como ya se habían pronunciado a este respecto Ulpiano en D. 12.6.26.1 y Justiniano en CJ 4.32.26.1 y Novela 121 .

B) Exigir al acreedor que recalcule el préstamo, teniendo por no puesta la clausula suelo, tal como estableció Diocleciano en una constitución recogida en el CJ 4.2.8.

C) Reducir ex officio iudicis los intereses que superen la cuantía lícita, tal como refería Paulo, en D.22.1.17 pr. $^{76}$ : Praesidem provinciae adi, qui stipulationem, de cuius iniquitate questus est, ad modum iustae exactionis rediget.

La denegación del despacho de ejecución viene regulada en el articulo 552 de la LEC, en cuyo apartado $1^{\circ}$ reformado por la disposición transitoria segunda de la Ley 42/2015, de 5 de octubre, de reforma de la Ley 1/2000, de 7 de enero, de Enjuiciamiento Civil («B.O.E.» 6 octubre) impone al tribunal la obligación de examinar de oficio si alguna de las cláusulas incluidas en un título ejecutivo de los citados en el artículo 557.1 puede ser calificada como abusiva. Cuando apreciare que alguna cláusula puede ser calificada como tal dará audiencia por

${ }^{73}$ CJ 4.32.18 Imperatores Diocletianus, Maximianus. Indebitas usuras, etiam si ante sortem solutae non fuerint ac propterea minuere eam non potuerint, licet post sortem redditam creditori fuerint datae, exclusa iuris varietate repeti posse pensa ratione firmatum est. * DIOCL. ET MAXIM. AA. ET CC. AURELIO CASTORI.

74 Cuincius, J, Opera Omnia. Lugdumi, 1606, p.434.

75 GLÜCK; F, Commentario alle pandette, traducido por Filippo Serafini, L.XXII, Milano, 1906, pp.105.

${ }^{76}$ D.22.1.17.pr. Paulus libro singulari de usuris: "Cum quidam cavisset se quotannis quincunces usuras praestaturum et, si quo anno non solvisset, tunc totius pecuniae ex die qua mutuatus est semisses soluturum, et redditis per aliquot annos usuris mox stipulatio commissa esset, divus Marcus fortunato ita rescripsit: "Praesidem provinciae adi, qui stipulationem, de cuius iniquitate questus est, ad modum iustae exactionis rediget". Haec constitutio ad finitum modum excedit: quid ergo? sic temperanda res est, ut in futurum dumtaxat ex die cessationis crescat usura". 
Intereses de prestamos de dinero: limitaciones legales y efectos civiles de su abusividade em el Derecho Romano

quince días a las partes. Oídas éstas, acordará lo procedente en el plazo de cinco días hábiles conforme a lo previsto en el artículo 561.1.3 ${ }^{\mathrm{a}}$, disponiendo el apartado $2^{\mathrm{o}}$ que el auto que deniegue el despacho de la ejecución será directamente apelable, sustanciándose la apelación sólo con el acreedor. También podrá el acreedor, a su elección, intentar recurso de reposición previo al de apelación.

Una vez firme el auto, que deniegue el despacho de la ejecución, el acreedor sólo podrá hacer valer sus derechos en el proceso ordinario correspondiente, si no obsta a éste la cosa juzgada de la sentencia, o resolución firme en que se hubiese fundado la demanda de ejecución. Por esta vía podría utilizarse la denegatio actionis.

Tambien nuestro ordenamiento jurídico prevee como instrumento de defensa que concede al deudor o ejecutado la oposición por la vía del articulo 557 1, apartados $3^{\circ}$ Pluspetición o exceso en la computación a metálico de las deudas en especie y $7^{\circ}$ Que el título contenga cláusulas abusivas, ordenándose, por el letrado de la administración de justicia, la suspensión del curso de la ejecución, tal como dispone el apartado $2^{\circ}$ del articulo 557 de la lec.

La reducción ex oficio iudicis exigiría una reforma legislativa, que quizá fuera conveniente realizar.

Respecto al resarcimiento del deudor, y en aquellos supuestos en que el Tribunal declare la no vinculación, y tenga por no puesta la clausula abusiva, las consecuencias serían diferentes según que el préstamo aun no hubiera sido devuelto por el acreedor, o en los supuestos que ya hubiera cumplido con su obligación, y el acreedor hubiera ya recuperado íntegramente el capital prestado.

Me parece totalmente acorde a derecho las soluciones que ofrecía el Derecho romano para éstos supuestos y que pueden adoptarse plenamente en estos momentos dentro de nuestro ordenamiento jurídico, de tal forma que:

1) Si el préstamo aún no ha sido devuelto totalmente al acreedor, el tribunal deberá declarar la no vinculación, y tener por no puesta la clausula abusiva. Respecto a las cantidades abonadas hasta la declaración de abusividad, las mismas deberán ser imputadas al capital, disminuyendo éste desde el principio, esto es, con efectos ex tunc, sin que proceda la devolución al deudor, tal como disponía Ulpiano en D.12.6.26 por Justiniano en CJ 4.32.26.1 y Novela 121 .

2) En los supuestos en que el capital se haya devuelto por el deudor íntegramente al acreedor, en este caso, nos encontrariamos ante un cobro de lo indebido, tal como apuntó Ulpiano en D.12.6.26.Pr., y Paulo en Sentencias 2.14.2, de forma que procedería la devolución de lo abonado indebidamente, siempre que se den los requisitos de los articulos 1895 y ss del Código Civil, que exige error o ignorancia, tal como ya requerían los juristas romanos en D.12.6.1; D.12.6.7, D.12.16.19.1, y posteriormente se recogió en CJ 6.5.1.

Si una persona abonó a sabiendas los intereses pactados en la claúsula suelo, no lo repite con razón y no podrá prosperar la acción del cobro de lo indebido, tal como se establece en los artículos 1895 y ss, y se recogia en las fuentes jurídico romanas en D.12.6.1; CJ 6.5.9.pr.

Por todo ello, para determinar si procede o no la devolución de los intereses por parte del acreedor, es preciso acreditar, por la persona que efectuó el pago, el error o la ignorancia tal como dispone el artículo 1.900 del Codigo civil.

Los problemas de prueba existieron ya desde antiguo, y por ello es necesario plantearse qué solución deberían dar los tribunales a aquellos supuestos, en que se hubiere pagado los 
intereses de la cláusula suelo, por razón de la duda, tanto de la inclusión de la misma en la escritura de hipoteca, como de su funcionamiento.

Este caso también se planteó en el Derecho romano y en un texto recogido en CJ. 4.6.11 $1^{77}$ se debatió si podían repetir o no lo que hubieren pagado con ánimo incierto. Los emperadores mandaron que a ninguno de los que con ánimo incierto hubieren dado dinero no debido, o hubieren pagado alguna otra cosa, se le deniege la repetición, y que no se alegue contra ellos la presunción de transacción, si esta no se probase especialmente por la otra parte.

Estas soluciones jurídicas son totalmente acordes tanto al derecho comunitario como al derecho español, esperando que sean estudiadas y analizadas, tanto por el legislador como por la jurisprudencia, para solucionar los problemas derivados de tener por no puestas las llamadas cláusula suelo, pues de ésta forma no se altera el orden socio-económico en que fundamenta el TS su decisión de limitar los efectos de la retroactividad, y se da cumplimiento al articulo 83 de la LGCYU $^{78}$.

En definitiva, una vez más se pone de manifiesto el hecho de que el Derecho privado europeo, y el Derecho privado comparado en general, suponen una actualización y adaptación a las necesidades modernas de viejas concepciones, acuñadas por la ciencia jurídica romana, a la que siempre hay que mirar, pues estos problemas ya se planteraon y fueron resueltos de una forma equilibrada y práctica, valorando los intereses en juego en el negocio, y la solución mas equitativa y justa para todas las partes implicadas en el negocio jurídico.

Recebido em: 28 set. 2017.

Aceito em: 26 fev. 2018.

77 CJ. 4.6.11 Imperator Justinianus. "Pro dubietate eorum, qui mente titubante indebitam solverunt pecuniam, certamen legislatoribus incidit, utrumne id, quod ancipiti animo persolverunt, possint repetere an non. 1. Quod nos decidentes sancimus omnibus, qui incerto animo indebitam dederunt pecuniam vel aliam quandam speciem persolverunt, repetitionem non denegari et praesumptionem transactionis non contra eos induci, nisi hoc specialiter ab altera parte approbetur. * IUST. A. IULIANO PP. *<A 530 D. K. OCT. CONSTANTINOPOLI LAMPADIO ET ORESTA VV. CC. CONSS.>"

78 Artículo 83 del Real Decreto Legislativo 1/2007, de 16 de noviembre, por el que se aprueba el texto refundido de la Ley General para la Defensa de los Consumidores y Usuarios y otras leyes complementarias( LGDCYU): Nulidad de las cláusulas abusivas y subsistencia del contrato. Las cláusulas abusivas serán nulas de pleno derecho y se tendrán por no puestas. A estos efectos, el Juez, previa audiencia de las partes, declarará la nulidad de las cláusulas abusivas incluidas en el contrato, el cual, no obstante, seguirá siendo obligatorio para las partes en los mismos términos, siempre que pueda subsistir sin dichas cláusulas. 